\title{
Cerebral Cortex
}

National Cancer Institute

\section{Source}

National Cancer Institute. Cerebral Cortex. NCI Thesaurus. Code C12443.

The outer layer of the cerebrum composed of neurons and unmyelinated nerve fibers. It is responsible for memory, attention, consciousness and other higher levels of mental function. 